\title{
Predictors of adherence to antihypertensive medication in northern United Arab Emirates
}

\author{
R.J.K. Bader, ${ }^{7}$ F. Koprulu, ${ }^{2}$ N.A.G.M. Hassan, ${ }^{3}$ A.A.A. Ali ${ }^{3}$ and A.A. Elnour ${ }^{4}$
}

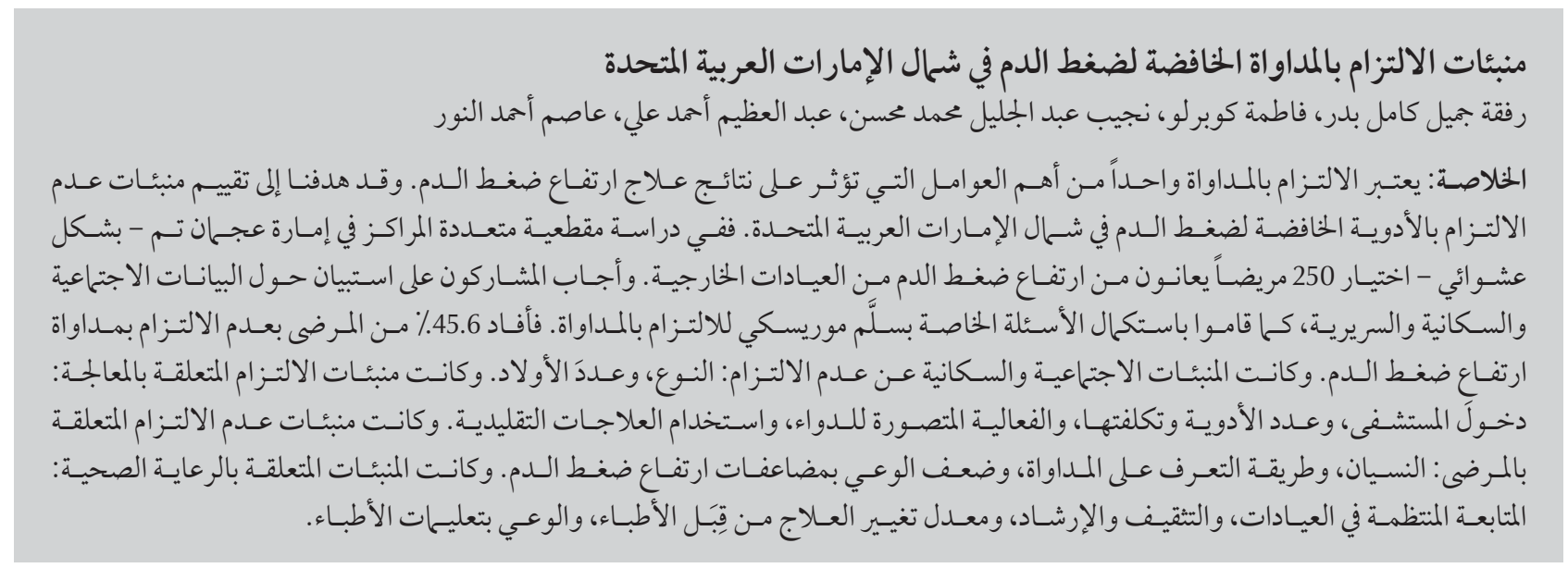

ABSTRACT This study aimed to assess the predictors of non-adherence to antihypertensive medications in northern United Arab Emirates. In a cross-sectional, multicentre study in Ajman Emirate, 250 patients with hypertension were randomly selected from outpatient clinics. Participants answered an interview questionnaire about sociodemographic and clinical data and completed the Morisky medication adherence scale. Non-adherence to antihypertensive medication was reported by $45.6 \%$ of patients. Sociodemographic predictors of non-adherence were sex and number of children. Therapy-related predictors of adherence were hospital admissions, number and cost of medications, medication perceived effectiveness and use of traditional remedies. Patient-related predictors of non-adherence were forgetfulness, method of identifying medication and poor awareness of hypertension complications. Health-care-related predictors were regular follow up at clinics, education and counselling, frequency of changing medication by physicians and awareness of physicians' instructions.

\section{Facteurs prédictifs de l'adhésion aux traitements antihypertenseurs dans le nord des Émirats arabes unis}

RÉSUMÉ Notre étude avait pour objectif d'évaluer les facteurs prédictifs de la non-adhésion aux traitements antihypertenseurs dans le nord des Émirats arabes unis. Dans une étude multicentrique transversale réalisée dans l'Émirat d'Ajman, 250 patients hypertendus ont été sélectionnés aléatoirement dans des centres de consultations externes. Les participants ont répondu à un questionnaire administré par entretien sur leurs données sociodémographiques et cliniques et ont renseigné l'échelle de Morisky sur l'adhésion au traitement. La nonadhésion aux traitements antihypertenseurs a été rapportée par 45,6\% des patients. Les facteurs prédictifs sociodémographiques de la non-adhésion étaient le sexe et le nombre d'enfants. L'admission en établissement hospitalier, le nombre etle coût des traitements, la perception del'efficacité du traitementetl'utilisation de remèdes traditionnelsétaientdesfacteursprédictifs del'adhésionliésautraitement. Lesfacteursprédictifsdelanon-adhésion liés aux patients étaient le manque de mémoire, la méthode d'identification des traitements et une faible sensibilisation aux complications de l'hypertension. Les facteurs prédictifs liés aux soins de santé étaient un suivi régulier en centre de soins, l'éducation et les conseils, la fréquence des modifications des traitements par les médecins et la sensibilisation à leurs instructions.

${ }^{7}$ GulfMedical Centre Al-Noor Pharmacy, Ajman, United Arab Emirates. ${ }^{2}$ Department of Medicinal Chemistry; ${ }^{3}$ Department of Pharmacology and Clinical Pharmacy, College of Pharmacy and Health Sciences, Ajman University of Sciences and Technology, Ajman, United Arab Emirates. ${ }^{4}$ Department of Pharmacology, College of Medicine and Health Sciences, United Arab Emirates University, Al Ain, United Arab Emirates (Correspondence to A.A. Elnour: assahura1962@gmail.com).

Received: 30/09/14; accepted: 12/02/15 


\section{Introduction}

Hypertension is a major risk factor for cardiovascular disease and it is one of the most common chronic diseases in the United Arab Emirates (UAE) (1). The UAE is a modern and prosperous society with sedentary lifestyles and high cardiovascular disease risk profiles $(2,3)$. In 2010 a report of mortality rates in Abu Dhabi Emirate showed that the top cause of mortality for both UAE nationals and expatriates was circulatory system diseases, accounting for at least $27 \%$ of deaths. The age-standardized mortality rates for cardiovascular disease were also significantly higher in the UAE as compared with other countries (1).

Management of hypertension places great challenges on both patients and health-care professionals. Successful control of blood pressure is important for the reduction of morbidity and mortality rates; several studies have demonstrated the impact of antihypertensive medication in improving clinical outcomes (4-6). Adherence to antihypertensive medication is one of the most important factors affecting hypertension management outcomes in terms of quality of life and complications $(5,7)$. Non-adherence to medication, which occurs for a number of different reasons, results in suboptimal blood pressure control, which can lead to cardiovascular events, mortality and increased health care costs (8).

Medication adherence is defined as "the extent to which patients take drugs as instructed by their health care practitioners" (9). A World Health Organization (WHO) report stated that poor adherence to medication is the most important cause of uncontrolled blood pressure and estimated that $52-74 \%$ of patients with high blood pressure do not take their antihypertensive medication as prescribed (10). Non-adherence remains a major problem among patients with hypertension and has been identified as one of the main causes of failure in achieving blood pressure control $(10,11)$.

Numerous studies have been conducted worldwide to investigate the level of medication adherence and factors affecting it. A review of studies performed in Middle Eastern countries highlighted the problem of non-adherence to medication among patients with chronic diseases (12). However, there was great variation in the reported rates of non-adherence across the countries, probably due to differences in the definitions of adherence/non-adherence used as well as to differences in the study designs. Some barriers and predictors of non-adherence among patients in this region were identified. However, the 19 studies reviewed did not enable meaningful conclusions regarding levels of adherence to be drawn. The review findings highlight the need to expand this area of research in the region and to improve the quality of such research. It concluded the need for further research on the rate of non-adherence and barriers to patients' adherence to their medication in order to identify the type of interventions $(12,13)$.

Only limited data from the UAE are available about adherence to medication among patients with hypertension, and the magnitude of and reasons for non-adherence to antihypertensive medication has not been well investigated in this population. We therefore aimed to assess medication adherence and factors predicting non-adherence in patients with hypertension attending multicentre, outpatient hypertension clinics covering both government and private sectors. The objective was to inform the current clinical practice about adherence to antihypertensive medication.

\section{Methods}

\section{Study design and sites}

A multicentre, cross-sectional study was conducted in Ajman Emirate in the UAE from March 2012 to April 2013. The study sites were 5 outpatient hypertension clinics in 2 government and private hospitals and 3 private clinics. Stratified random sampling was used in selecting the main clinics, based on the geographical distribution as 2 main hospitals (out of 8) and 3 main hypertension private clinics (out of 12).

The study was ethically approved by the health authorities in each of the surveyed facilities and the institutional ethics review board of the university.

\section{Sample and sampling procedure}

The following assumptions were made to estimate the sample size. In the absence of any previous data from the UAE, $80 \%$ was taken as the prevalence of non-adherence among patients with chronic disease based on pilot study data, with 95\% confidence level and margin of error $5 \%(d=0.05)$. The following formula was used to estimate the sample size: $n=(Z \alpha / 2)^{2} \times P(1-P) / m^{2}$

Where $n=$ required sample size; $Z=$ confidence level at 95\% (standard value of 1.96); $P=$ estimated prevalence of non-adherence based on pilot study results $(\approx 80 \%)$; $m=$ margin of error at $5 \%$ (standard value of 0.05 ). Computing with the above formula gave a total sample size of 246 . Hence, we chose 265 as the sample size to account for any dropouts or lost subjects. We also confirmed the appropriate calculated sample size against previous results from the literature as a benchmark to estimate the prevalence of adherence.

The population covered by these facilities was nearly 500 000. Patients visiting the clinics comprised the study population. The study sample were patients with hypertension selected randomly (using consecutive sampling) from the registries of the outpatient hypertension clinics in the surveyed facilities. We included patients diagnosed with hypertension for 1 year or more, of both sexes, aged $>18$ years, having no hypertension-related complications 
and willing to participate in the study. Any patients who were pregnant or breastfeeding were excluded from the study. We recruited 53 patients from each clinic (total 265).

\section{Data collection}

\section{Questionnaires}

We developed and validated a study questionnaire to obtain data from patients on factors predicting adherence to antihypertensive medication. The questionnaire comprised 3 subsections: disease status and medication-related factors (10 items), patient-related factors ( 7 items) and health-care system factors (4 items). The questionnaire was delivered in a structured interview. The validation involved translation and assessing the cross-cultural validity of the tool. The piloting of the developed tool was performed on a sample of 40 patients with hypertension who were selected based on similarity to the study sample. The questionnaire was modified as appropriate and was tested for internal consistency reliability (i.e. calculating a reliability estimate based on a single form of a test administered on a single occasion using Cronbach alpha). The reliability analysis yielded an acceptable Cronbach alpha score of 0.71 .

\section{Morisky medication adherence scale}

We used the structured, validated Morisky medication adherence scale (MMAS-4) to measure adherence to antihypertensive medication (14). The MMAS-4 is a generic self-reported, medication-taking behaviour scale in which the specific health issue (e.g. high blood pressure) is inserted for the "health concern". The MMAS-4 consists of 4 items with a scoring scheme of yes $=0$ and no $=1$. The items are summed to give a range of scores from 0 to 4 . The scale items for this survey were: "Do you ever forget to take your antihypertensive medication?"; "Do you have problems remembering to take your antihypertensive medication?"; "When you feel better, do you stop taking your antihypertensive medication?"; and "Sometimes if you feel worse when you take your antihypertensive medication, do you stop taking it?"

The original English version was translated into Arabic language (forward and backward translation) and tested for validity. The translated Arabic version of the MMAS-4 score was tested for reliability via a procedure that included a review of questions and responses by expert pharmacists $(n=$ 6) from the College of Pharmacy in Ajman University of Science and Technology. Furthermore, a pilot study was conducted on a sample of 40 patients with hypertension who were selected based on their similarity to the study sample. The pilot phase showed that the questionnaire was able to collect the required information and the ease and clarity of the questions were ensured. The translated version was tested for internal consistency reliability as before and yielded an acceptable Cronbach alpha score of 0.82 .

\section{Procedure}

Patients who met the inclusion criteria were informed about the purpose of the study and invited to participate, and subjects who agreed to participate signed the consent form. The recruited patients were interviewed to fill the study baseline questionnaire (sociodemographic and clinical data) and the MMAS-4. Clinical data, including blood pressure readings, prescribed medication and comorbidities were obtained from the patients' electronic medical records as appropriate. Followup data (e.g. blood pressure readings) was obtained during patients' clinic visits. Recruited patients were followed up for a period of 1 year. Participants were not given any reward or compensation for participating.

\section{Data analysis}

The primary outcome was the scores of MMAS-4 and the interview questionnaire. Respondents with MMAS-4 scores < 3 were considered as non-adherent and those with scores of 3-4 were considered adherent to antihypertensive medication. The measurement of the overall non-adherence level to antihypertensive medication was based on the 4 items of the MMAS4 score.

The data were analysed using SPSS, version 21. Descriptive statistics were done for demographic data. The chisquared test was applied to assess the association of different sociodemographic data with adherence to antihypertensive medication. In cases with cell counts below 5 , the significance of results were analysed with Fisher exact test. $P$-value $<0.05$ was considered to be statistically significant. We used multivariate regression analysis to identify the predictors of adherence and to relate adherence to antihypertensive medication with other factors (disease and medication-related, patient-related and health system-related variables).

\section{Results}

\section{Background sociodemographic data}

From the 265 recruited patients 15 were lost to follow up and therefore the final number of participants who completed the study was 250 (response rate 94.3\%). The sociodemographic characteristics of these patients were 134 (53.6\%) males and $116(46.4 \%)$ females, with a mean age of 44 [standard deviation (SD) 5.6] years (Table 1). The majority were married (77.2\%), had $\geq 2$ children $(79.6 \%)$ and were aged $\geq 50$ years (64.4\%). There was a high proportion with secondary or university education (78.0\%). A total of $60.0 \%$ were in employment and most of the sample were classified as having a low monthly income, i.e. $<5000$ Arab Emirati dirham (AED). 


\begin{tabular}{|c|c|c|}
\hline Respondents' characteristics & No. & $\%$ \\
\hline \multicolumn{3}{|l|}{ Age (years) } \\
\hline$<50$ & 89 & 35.6 \\
\hline$\geq 50$ & 161 & 64.4 \\
\hline \multicolumn{3}{|l|}{ Sex } \\
\hline Male & 134 & 53.6 \\
\hline Female & 116 & 46.4 \\
\hline \multicolumn{3}{|l|}{ Nationality } \\
\hline UAE & 74 & 29.6 \\
\hline Expatriate & 176 & 70.4 \\
\hline \multicolumn{3}{|l|}{ Level of education } \\
\hline None/ primary & 55 & 22.0 \\
\hline Secondary/ university & 195 & 78.0 \\
\hline \multicolumn{3}{|l|}{ Marital status } \\
\hline Single/ divorced & 57 & 22.8 \\
\hline Married & 193 & 77.2 \\
\hline \multicolumn{3}{|l|}{ No. of children } \\
\hline $0-1$ & 51 & 20.4 \\
\hline$\geq 2$ & 199 & 79.6 \\
\hline \multicolumn{3}{|l|}{ Occupation } \\
\hline Employed & 150 & 60.0 \\
\hline Unemployed & 100 & 40.0 \\
\hline \multicolumn{3}{|l|}{ Monthly income (AED) } \\
\hline$<5000$ & 89 & 64.4 \\
\hline$\geq 5000$ & 161 & 35.6 \\
\hline \multicolumn{3}{|l|}{ Health insurance card } \\
\hline Yes & 144 & 57.6 \\
\hline No & 106 & 42.4 \\
\hline
\end{tabular}

$U A E=$ United Arab Emirates $; A E D=$ Arab Emirati dirham.

\section{Non-adherence to antihypertensive medication}

A total of 114 patients were determined to be non-adherers to antihypertensive medication (i.e. MMAS-4 scores < 3), a non-adherence rate of $45.6 \%$. The overall MMAS-4 score for non-adherence to antihypertensive medication was $<2$ (SD 0.23).

\section{Sociodemographic predictors of adherence to antihypertensive medication}

Table 2 shows that the only sociodemographic variables that were significantly associated with non-adherence to antihypertensive medication were sex and number of children. More males were antihypertensive medication: duration of disease, comorbidity, symptoms of hypertension (e.g. headache), medication side-effects and blood pressure control $(P>0.05)$. On the other hand, hospital admission was a significant factor, whereby patients who had $\geq 1$ admissions to hospital had a higher rate of non-adherence to antihypertensive medication as compared with their counterparts with $<1$ admission $(P<$ 0.05 ). Patients on $\geq 2$ antihypertensive medication were more non-adherent than those on only 1 type of medication. The patients' perceived effectiveness of antihypertensive medication, the cost of medication and the patients' use of traditional remedies also showed a significant association with non-adherence to antihypertensive medication $(P<0.05)$ (Table 3).

\section{Patient-related factors}

The patient-related factors that were significantly associated with non-adherence to antihypertensive medication were forgetfulness, being aware of the complications of hypertension $(P<$ $0.001)$ and the method of identifying their medication $(P<0.01)$. Patients who identified their antihypertensive medicine by the colour or shape of the package were more non-adherent than those who knew the name of their medication. On the other hand, patients' beliefs regarding their medication and the seriousness of their condition, trusting the physician's diagnosis, regular blood pressure monitoring and awareness of the importance of diet in controlling their blood pressure did not show any significant association with adherence to antihypertensive medication (Table 4). Although those without family support tended to more non-adherent, the numbers were very small and the difference was not statistically significant $(P$ $=0.45)$. 


\begin{tabular}{|c|c|c|c|c|c|c|}
\hline \multirow[t]{2}{*}{ Respondents' characteristics } & \multicolumn{2}{|c|}{ Non-adherence } & \multicolumn{2}{|c|}{ Adherence } & \multirow[t]{2}{*}{$x^{2}$} & \multirow[t]{2}{*}{$P$-value } \\
\hline & No. & $\%$ & No. & $\%$ & & \\
\hline \multicolumn{7}{|l|}{ Age (years) } \\
\hline$<50$ & 39 & 43.8 & 50 & 56.2 & \multirow{2}{*}{0.17} & \multirow{2}{*}{0.67} \\
\hline$\geq 50$ & 75 & 46.6 & 86 & 53.4 & & \\
\hline \multicolumn{7}{|l|}{ Sex } \\
\hline Male & 71 & 53.0 & 63 & 47.0 & \multirow{2}{*}{6.4} & \multirow{2}{*}{0.01} \\
\hline Female & 43 & 37.1 & 73 & 62.9 & & \\
\hline \multicolumn{7}{|l|}{ Nationality } \\
\hline UAE & 31 & 41.9 & 43 & 58.1 & \multirow{2}{*}{0.64} & \multirow{2}{*}{0.42} \\
\hline Expatriate & 83 & 47.2 & 93 & 52.8 & & \\
\hline \multicolumn{7}{|l|}{ Level of education } \\
\hline None/ primary & 27 & 49.1 & 28 & 50.9 & \multirow{2}{*}{0.34} & \multirow{2}{*}{0.55} \\
\hline Secondary/ university & 87 & 44.6 & 108 & 55.4 & & \\
\hline \multicolumn{7}{|l|}{ Marital status } \\
\hline Single/ divorced & 29 & 50.9 & 28 & 49.1 & \multirow{2}{*}{0.83} & \multirow{2}{*}{0.36} \\
\hline Married & 85 & 44.0 & 108 & 56.0 & & \\
\hline \multicolumn{7}{|l|}{ No. of children } \\
\hline $0-1$ & 30 & 58.8 & 21 & 41.2 & \multirow{2}{*}{4.5} & \multirow{2}{*}{0.03} \\
\hline$\geq 2$ & 84 & 42.2 & 115 & 57.8 & & \\
\hline \multicolumn{7}{|l|}{ Occupation } \\
\hline Employed & 68 & 45.3 & 82 & 54.7 & \multirow{2}{*}{0.01} & \multirow{2}{*}{0.92} \\
\hline Unemployed & 46 & 46.0 & 54 & 54.0 & & \\
\hline \multicolumn{7}{|l|}{ Monthly income (AED) } \\
\hline$<5000$ & 41 & 46.1 & 48 & 53.9 & \multirow{2}{*}{0.07} & \multirow{2}{*}{0.78} \\
\hline$\geq 5000$ & 73 & 45.3 & 88 & 54.7 & & \\
\hline \multicolumn{7}{|l|}{ Have health insurance } \\
\hline Yes & 59 & 41.0 & 85 & 59.0 & \multirow{2}{*}{2.93} & 09 \\
\hline No & 55 & 51.9 & 51 & 48.1 & & 0.09 \\
\hline
\end{tabular}

$U A E=$ United Arab Emirates $; A E D=$ Arab Emirati derham.

\section{Health care system-related factors}

Table 5 showed the association between non-adherence to antihypertensive medication and predictors related to the health-care system. Patients whose last clinic visit was $>1$ month ago were significantly more likely to be nonadherers $(P<0.001)$. Patients who had had any form of medication education (offered by health-care providers) were more adherent to their antihypertensive medication as compared with their counterparts who had not $(P<0.001)$. Patients whose antihypertensive drugs were changed more than once by the physician were significantly more likely to be non-adherers $(P=0.02)$. There was a significant association between patients' awareness of their physician's instructions regarding their medication and non-adherence to antihypertensive medication $(P<0.001)$.

\section{Discussion}

We assessed medication adherence in patients with hypertension in multicentre outpatient hypertension clinics settings covering both government and private sectors. The status of adherence and factors associated with non-adherence to antihypertensive medication were examined with a validated MMAS4 score and a multifaceted validated questionnaire.

The MMAS-4 scores yielded a rate of non-adherence to antihypertensive medication of nearly $50 \%$. This is similar to the WHO reported range of $50-70 \%$ as the extent to which patients adhere to pharmacotherapy for hypertension (15). Our finding is consistent with other international studies (15-18), including studies conducted in the Middle East (19-24). The latest 7 studies conducted in the Middle East among hypertensive patients have reported medication non-adherence rates between $23 \%$ and $49.5 \%$. 


\begin{tabular}{|c|c|c|c|c|c|c|}
\hline \multirow[t]{2}{*}{ Disease and therapy- related variables } & \multicolumn{2}{|c|}{ Non-adherence } & \multicolumn{2}{|c|}{ Adherence } & \multirow[t]{2}{*}{$x^{2}$} & \multirow[t]{2}{*}{$P$-value } \\
\hline & No. & $\%$ & No. & $\%$ & & \\
\hline \multicolumn{7}{|l|}{ Hypertension duration $^{b}$ (years) } \\
\hline$\geq 2$ & 26 & 45.6 & 31 & 54.4 & \multirow{2}{*}{0.51} & \multirow{2}{*}{0.91} \\
\hline$\leq 2$ & 98 & 48.3 & 105 & 51.7 & & \\
\hline \multicolumn{7}{|l|}{ Having other disease(s) (comorbidity) } \\
\hline Yes & 60 & 49.2 & 62 & 50.8 & \multirow{2}{*}{1.2} & \multirow{2}{*}{0.27} \\
\hline No & 54 & 42.2 & 74 & 57.8 & & \\
\hline \multicolumn{7}{|l|}{ Have symptoms of high blood pressure ${ }^{c}$} \\
\hline Yes & 66 & 46.2 & 77 & 53.8 & \multirow{2}{*}{0.04} & \multirow{2}{*}{0.84} \\
\hline No & 48 & 44.9 & 59 & 55.1 & & \\
\hline \multicolumn{7}{|l|}{ No. of hospital admissions } \\
\hline$\leq 1$ & 92 & 43.0 & 122 & 57.0 & \multirow{2}{*}{4.08} & \multirow{2}{*}{0.04} \\
\hline$>1$ & 22 & 61.1 & 14 & 38.9 & & \\
\hline \multicolumn{7}{|l|}{ Blood pressure } \\
\hline Controlled & 70 & 44.0 & 89 & 56.0 & \multirow{2}{*}{0.44} & \multirow{2}{*}{0.51} \\
\hline Uncontrolled & 44 & 48.3 & 47 & 51.6 & & \\
\hline \multicolumn{7}{|l|}{ No. of medications taken for hypertension } \\
\hline 1 & 33 & 37.5 & 55 & 62.5 & \multirow{2}{*}{3.8} & \multirow{2}{*}{0.05} \\
\hline$\geq 2$ & 81 & 50.3 & 80 & 49.7 & & \\
\hline \multicolumn{7}{|l|}{ Medication perceived as effective } \\
\hline Yes & 12 & 85.7 & 2 & 14.3 & \multirow{2}{*}{4.89} & \multirow{2}{*}{$0.03^{\mathrm{a}}$} \\
\hline No & 98 & 55.4 & 79 & 44.6 & & \\
\hline \multicolumn{7}{|l|}{ Side-effects } \\
\hline Yes & 14 & 60.9 & 9 & 39.1 & \multirow{2}{*}{0.12} & \multirow{2}{*}{0.73} \\
\hline No & 96 & 57.1 & 72 & 42.9 & & \\
\hline \multicolumn{7}{|l|}{ Cost of medication (AED) } \\
\hline$\leq 600$ & 68 & 38.9 & 107 & 61.1 & 107 & $<0001$ \\
\hline$>600$ & 46 & 61.3 & 29 & 38.7 & 10.7 & -0.001 \\
\hline Use traditional/alternative therapies & & & & & & \\
\hline Yes & 56 & 73.7 & 20 & 26.3 & 129 & $<0 \Omega 01$ \\
\hline No & 54 & 47.4 & 60 & 52.6 & 12.3 & -0.001 \\
\hline
\end{tabular}

${ }^{a}$ Fisher exact test.

${ }^{b}$ Time elapsed since first started antihypertensive medication; ' Symptoms such as headache $A E D=$ Arab Emirati derham .

Our results concerning the demographic predictors of non-adherence suggested that there were no differences between age groups regarding adherence to antihypertensive medication. This contradicts the findings of 2 other studies $(25,26)$, which might be attributed to the dichotomous age grouping ( $\geq 50$ and $<50$ years) in our study rather than to the age variable itself. We found that male patients were more non-adherent to medication as compared with females and this finding is in agreement with other studies $(25,27)$. In contrast, Holt et al. showed no differences between the sexes regarding adherence to medication (28) and Shan et al. found that females were more non-adherent to medication than males (29).

To the best of our knowledge there are no reported studies on the relation between the number of children and the level of non-adherence to medication which we addressed in our study. There was a significant association between having a higher number of children and non-adherence. This might be attributed to other reasons such as the stress of responsibility or to the financial burden of a higher number of children on the family.

The factors that significantly predicted patients' adherence to antihypertensive medication pertinent to disease status and medication were: hospital admissions, cost of medication, perceived effectiveness of medication and use of traditional remedies. Those patients who were admitted to hospital 


\begin{tabular}{|c|c|c|c|c|c|c|}
\hline \multirow[t]{2}{*}{ Patient-related variables } & \multicolumn{2}{|c|}{ Non-adherence } & \multicolumn{2}{|c|}{ Adherence } & \multirow[t]{2}{*}{$x^{2}$} & \multirow[t]{2}{*}{$P$-value } \\
\hline & No. & $\%$ & No. & $\%$ & & \\
\hline \multicolumn{7}{|l|}{ Forgetfulness } \\
\hline Yes & 94 & 76.4 & 29 & 23.6 & \multirow{2}{*}{51.2} & \multirow{2}{*}{$<0.001$} \\
\hline No & 16 & 23.2 & 53 & 76.8 & & \\
\hline \multicolumn{7}{|l|}{ Not trusting physician's diagnosis } \\
\hline Yes & 4 & 66.7 & 2 & 33.3 & \multirow{2}{*}{0.21} & \multirow{2}{*}{$0.64^{a}$} \\
\hline No & 106 & 57.3 & 79 & 42.7 & & \\
\hline \multicolumn{7}{|l|}{ Family support } \\
\hline Yes & 105 & 57.1 & 79 & 42.9 & \multirow{2}{*}{0.57} & \multirow{2}{*}{$0.45^{\mathrm{a}}$} \\
\hline No & 5 & 71.4 & 2 & 28.6 & & \\
\hline \multicolumn{7}{|c|}{ Aware of hypertension complications } \\
\hline Yes & 78 & 40.6 & 114 & 59.4 & \multirow{2}{*}{8.26} & \multirow{2}{*}{$<0.001$} \\
\hline No & 36 & 62.1 & 22 & 37.9 & & \\
\hline \multicolumn{7}{|l|}{$\begin{array}{l}\text { Method of identifying } \\
\text { antihypertensive medication }\end{array}$} \\
\hline Colour or shape of package & 54 & 56.3 & 42 & 43.8 & \multirow{2}{*}{7.12} & \multirow{2}{*}{0.01} \\
\hline Name of drug & 60 & 39.0 & 94 & 61.0 & & \\
\hline \multicolumn{7}{|l|}{ Check blood pressure daily } \\
\hline Yes & 40 & 44.9 & 49 & 55.1 & \multirow{2}{*}{0.02} & \multirow{2}{*}{0.88} \\
\hline No & 74 & 46.0 & 87 & 54.0 & & \\
\hline \multicolumn{7}{|l|}{$\begin{array}{l}\text { Believe in importance of diet in } \\
\text { controlling blood pressure }\end{array}$} \\
\hline Yes & 106 & 46.5 & 122 & 53.5 & \multirow{2}{*}{0.83} & \multirow{2}{*}{0.36} \\
\hline No & 8 & 36.4 & 14 & 63.6 & & \\
\hline
\end{tabular}

${ }^{a}$ Fisher exact test.

more than once during the previous year exhibited greater non-adherence to antihypertensive medication as compared with those who were not admitted or admitted only once. This finding is consistent with most literature regarding the effect of hospital admissions on non-adherence $(30,31)$. Therefore, hospital admission can be targeted as a good predictor for medication nonadherence, as it provides an opportunity for health-care practitioners to target those patients and monitor them.

Among the disease-related variables which we assessed there were no significant correlations between patients who had comorbidities and patients who only had hypertension, which contrasts with the findings in some other studies $(29,32)$.

Medication-related factors indicated that patients who were taking more than one hypertension medication were less likely to adhere. This finding is in agreement with other studies, $(30,31)$, although the study of Natarajan et al. showed the opposite (33). Although patients who suffered from side-effects showed a higher non-adherence rate than those without side-effects in our study (60.9\% versus $39.1 \%)$ this variable was not a statistically significant predictor of non-adherence. This is inconsistent with some studies $(21,24,34)$, although the discrepancy may be because these researchers used a different expression to measure this variable ("stop taking medications if the patient felt worse").

Patients' perceptions of the effectiveness of their medication was another significant factor predicting medication adherence in our study, as patients who felt that their medication was ineffective were more likely to be non-adherent. Similarly, patients who used herbal or traditional remedies were less compliant with hypertension medication. These findings are similar to another study (35).

Regarding financial factors, a higher cost of hypertension medication had a significant association with non-adherence, as reported previously (36). Although the UAE is one of the highest income countries in the WHO Eastern Mediterranean Region, the minimum national wage is less in the northern Emirates as compared with the other, richer Emirates of Dubai and Abu Dhabi. Increasing living costs in the UAE may have led some patients with hypertension to consider their medication costs as a lower priority option. Also another possible reason is that $40 \%$ 


\begin{tabular}{|c|c|c|c|c|c|c|}
\hline \multirow[t]{2}{*}{ Health-care system variables } & \multicolumn{2}{|c|}{ Non-adherence } & \multicolumn{2}{|c|}{ Adherence } & \multirow[t]{2}{*}{$\chi^{2}$} & \multirow[t]{2}{*}{$P$-value } \\
\hline & No. & $\%$ & No. & $\%$ & & \\
\hline \multicolumn{7}{|l|}{ Last clinic follow up (months) } \\
\hline$\leq 1$ & 21 & 23.3 & 69 & 76.7 & \multirow{2}{*}{28.1} & \multirow{2}{*}{$<0.001$} \\
\hline$>1$ & 93 & 58.1 & 67 & 41.9 & & \\
\hline \multicolumn{7}{|l|}{$\begin{array}{l}\text { Received education and } \\
\text { counselling sessions }\end{array}$} \\
\hline Yes & 17 & 27.0 & 46 & 73.0 & \multirow{2}{*}{11.8} & \multirow{2}{*}{$<0.001$} \\
\hline No & 97 & 51.9 & 90 & 48.1 & & \\
\hline \multicolumn{7}{|l|}{$\begin{array}{l}\text { No. of times drugs changed by } \\
\text { physician }\end{array}$} \\
\hline$\leq 1$ & 61 & 38.4 & 98 & 61.6 & \multirow{2}{*}{9.21} & \multirow{2}{*}{0.02} \\
\hline$>1$ & 53 & 58.2 & 38 & 41.8 & & \\
\hline \multicolumn{7}{|l|}{ Aware of physician's instructions } \\
\hline Yes & 101 & 43.0 & 134 & 57.0 & \multirow{2}{*}{10.9} & \multirow{2}{*}{$<0.001^{\mathrm{a}}$} \\
\hline No & 13 & 86.7 & 2 & 13.3 & & \\
\hline
\end{tabular}

${ }^{a}$ Fisher exact test.

of the participants in this study were unemployed.

The patient-related factors significantly associated with non-adherence to antihypertensive medication were patients' method of identification of their medication and awareness of hypertension complications. This is in agreement with some other studies in the Middle East $(21,24)$ and elsewhere $(27,37)$. Only a small number of patients were not receiving assistance from others (family) to take their medication and they tended to more non-adherent than those with family support; however, the difference was not statistically significant. Studies in other countries have shown that family support is important in adherence to medication $(27,37,38)$. To our knowledge, there are no studies reporting the association between the methods patients use to identify medication and non-adherence. We showed that patients who identified their medication by the colour or shape of the package were more non-adherent than those who were familiar with the names of the medication. Another study examined the effect of a medication calendar in improving patients' adherence (39). Therefore, some patients may need to be educated to memorize their medication names and assessed for their ability to identify their medication by name.

Health-care system factors significantly associated with adherence to antihypertensive medication were: regular clinic follow-ups, education and counselling by health-care professionals, more than one change in antihypertensive therapy and awareness of the physician's instructions. This was in agreement with some other studies in the Middle East which also showed that irregularity of clinic follow-up (23) and lack of health education were significant factors in non-adherence to antihypertensive medication (24). Regular follow up at clinics was reported previously as a factor having a positive impact on patients' adherence (40). Physicians' communication with patients with hypertension and clear instructions on antihypertensive medication were anticipated to affect patient's adherence positively. There was also a positive impact of the education and counselling (offered by health-care professionals) on patients' adherence to their antihypertensive medication as indicated in similar studies $(41,42)$. The frequency of medication changes by the physician affected our patients' adherence in a negative fashion, as reported in another study (43). This might be attributed to patients' confusion with frequent changes of medication.

There were several limitations to our study. We used a self-reported questionnaire (the MMAS-4) to evaluate patients' adherence which might overestimate the issue of adherence to antihypertensive medication. There is no gold standard for measuring adherence, and the selection of a particular method varies depending on the availability of tools and researcher preference and accordingly large deviations in the assessment of adherence will occur even in the same sample of patients. Also, this study did not target adolescents on hypertensive medication even though this age group has recently attracted researchers studying non-adherence. Lastly, we did not use randomization in the sample, therefore the generalizability of the results cannot be assured.

\section{Conclusions}

The rate of non-adherence to antihypertensive medication was similar to 
that reported elsewhere in the WHO Eastern Mediterranean Region and in many other international studies. The disease- and medication-related factors that were predictors of adherence to antihypertensive medication among patients with hypertension in the UAE were number of hospital admissions, number of medications, cost of medication, perceived effectiveness of medication and use of traditional remedies. The patient-related predictors of nonadherence were sex, number of children, methods of identification of medication and poor awareness of hypertension complications. Factors related to the health-care system that were predictors of non-adherence were regular follow up at clinics, education and counselling offered by health-care professionals, frequency of changing drugs by physicians and awareness of doctor's instructions.

We recommend further research on predictors and barriers to patients' adherence to their antihypertensive medication in order to recognize and standardize the interventions that may be deployed for improving adherence. We suggest routine use of adherence questionnaires in hospitals to help to identify patients who are non-adherers to anti-hypertensive medication.

In order to link research to practice, the study results were disseminated to the local hospitals to implement adherence to antihypertensive medication as part of their care plan. The authors recommended assessing adherence to antihypertensive medication as part of the daily care plan. Electronic clinical decision-making systems for patient profiles should include tools for assessing patient adherence to medication.

\section{Funding: None.}

Competing interests: None declared.

\section{References}

1. Health statistics 2011. Abu Dhabi, UAE: Health Authority Abu Dhabi, 2011 (http://www.haad.ae/HAAD/LinkClick. aspx? fileticket=c-IGoRRszqc\%3d\&tabid=349, accessed 2 March 2015).

2. Hajat C, Harrison O, Shather Z. A profile and approach to chronic disease in Abu Dhabi. Global Health. 2012;8(1):18. PMID:22738714

3. Henry CJ, Lightowler HJ, Al-Hourani HM. Physical activity and levels of inactivity in adolescent females ages 11-16 years in the United Arab Emirates. Am J Hum Biol. 2004 MayJun;16(3):346-53. PMID:15101059

4. Chobanian AV, Bakris GL, Black HR, Cushman WC, Green LA, Izzo JL Jr, et al.; Joint National Committee on Prevention, Detection, Evaluation, and Treatment of High Blood Pressure. National Heart, Lung, and Blood Institute; National High Blood Pressure Education Program Coordinating Committee. Seventh report of the joint national committee on prevention, detection, evaluation, and treatment of high blood pressure. Hypertension. 2003 Dec;42(6):1206-52. PMID:14656957

5. Turnbull F, Neal B, Algert C, Chalmers J, Woodward M, Macmahon S, et al.; Blood Pressure Lowering Treatment Trialists Collaboration. Effects of different blood-pressure-lowering regimens on major cardiovascular events: results of prospectively-designed overviews of randomised trials. Lancet. 2003 Nov 8;362(9395):1527-35. PMID:14615107

6. Cushman WC, Ford CE, Cutler JA, Margolis KL, Davis BR, Grimm RH, et al.; ALLHAT Collaborative Research Group. Success and predictors of blood pressure control in diverse North American settings: the antihypertensive and lipid-lowering treatment to prevent heart attack trial (ALLHAT). J Clin Hypertens (Greenwich). 2002 Nov-Dec;4(6):393-404. PMID:12461301

7. Black HR, Elliott WJ, Neaton JD, Grandits G, Grambsch P, Grimm RH Jr, et al. Baseline characteristics and early blood pressure control in the CONVINCE trial. Hypertension. 2001 Jan;37(1):12-8. PMID:11208750

8. Haynes RB, Ackloo E, Sahota N, McDonald HP, Yao X. Interventions for enhancing medication adherence. Cochrane Database Syst Rev. 2008; (2):CD000011. PMID:18425859

9. Osterberg L, Blaschke T. Adherence to medication. N Engl J Med. 2005 Aug 4;353(5):487-97. PMID:16079372

10. Sabate E, editor. Adherence to long-term therapies: evidence for action. Geneva: World Health Organization; 2003 (http://
www.emro.who.int/ncd/Publications/adherence_report.pdf, accessed 2 March 2015)

11. Burnier M. Medication adherence and persistence as the cornerstone of effective antihypertensive therapy. Am J Hypertens. 2006 Nov;19(11):1190-6. PMID:17070434

12. Al-Qasem A, Smith F, Clifford S. Adherence to medication among chronic patients in Middle Eastern countries: review of studies. East Mediterr Health J. 2011 Apr;17(4):356-63. PMID:22259896

13. Fahey $\mathrm{M}$, et al. Measurement of adherence to anti-hypertensive 5.medication as perceived by doctors and patients. Qatar Med J. 2006;15:1-11.

14. Morisky DE, Green LW, Levine DM. Concurrent and predictive validity of a self-reported measure of medication adherence. Med Care. 1986 Jan;24(1):67-74. PMID:3945130

15. Adherence to long-term therapies: evidence for action1. Geneva: World Health Organization; 2003.

16. Alison Phillips L, Leventhal H, Leventhal EA. Assessing theoretical predictors of long-term medication adherence: patients' treatment-related beliefs, experiential feedback and habit development. Psychol Health. 2013;28(10):1135-51. PMID:23627524

17. Marcum ZA, Zheng Y, Perera S, Strotmeyer E, Newman AB, Simonsick EM, et al.; Health ABC Study. Prevalence and correlates of self-reported medication non-adherence among older adults with coronary heart disease, diabetes mellitus, and/or hypertension. Res Social Adm Pharm. 2013 NovDec;9(6):817-27. PMID:23291338

18. Park YH, Kim H, Jang SN, Koh CK. Predictors of adherence to medication in older Korean patients with hypertension. Eur J Cardiovasc Nurs. 2013 Feb;12(1):17-24. PMID:21704563

19. Hashmi SK, Afridi MB, Abbas K, Sajwani RA, Saleheen D, Frossard PM, et al. Factors associated with adherence to antihypertensive treatment in Pakistan. PLoS One. 2007;2(3):e280. PMID:17356691

20. Baune BT, Aljeesh YI, Bender R. The impact of non-compliance with the therapeutic regimen on the development of stroke among hypertensive men and women in Gaza, Palestine. Saudi Med J. 2004 Nov;25(11):1683-8. PMID:15573202

21. Youssef RM, Moubarak II. Patterns and determinants of treatment compliance among hypertensive patients. East Mediterr Health J. 2002 Jul-Sep;8(4-5):579-92. PMID:15603041 
22. Elzubier AG, Husain AA, Suleiman IA, Hamid ZA. Drug compliance among hypertensive patients in Kassala, eastern Sudan. East Mediterr Health J. 2000 Jan;6(1):100-5. PMID:11370321

23. Al-Sowielem LS, Elzubier AG. Compliance and knowledge of hypertensive patients attending PHC centers in Al-Khobar, Saudi Arabia. East Mediterr Health J. 1998;4:301-7.

24. Khalil SA, Elzubier AG. Drug compliance among hypertensive patients in Tabuk, Saudi Arabia. J Hypertens. 1997 May;15(5):561-5. PMID:9170010

25. Hyre AD, Krousel-Wood MA, Muntner P, Kawasaki L, DeSalvo KB. Prevalence and predictors of poor antihypertensive medication adherence in an urban health clinic setting. J Clin Hypertens (Greenwich). 2007 Mar;9(3):179-86. PMID:17344769

26. Lee GK, Wang HH, Liu KQ, Cheung Y, Morisky DE, Wong MC; LeeGKY. Determinants of medication adherence to antihypertensive medications among a Chinese population using Morisky Medication Adherence Scale. PLoS One. 2013;8(4):e62775. PMID:23638143

27. Ramli A, Ahmad NS, Paraidathathu T. Medication adherence among hypertensive patients of primary health clinics in Malaysia. Patient Prefer Adherence. 2012;6:613-22. PMID:22969292

28. Holt E, Joyce C, Dornelles A, Morisky D, Webber LS, Muntner $P$, et al. Sex differences in barriers to antihypertensive medication adherence: findings from the cohort study of medication adherence among older adults. J Am Geriatr Soc. 2013 Apr;61(4):558-64. PMID:23528003

29. Shah NR, Hirsch AG, Zacker C, Wood GC, Schoenthaler A, Ogedegbe G, et al. Predictors of first-fill adherence for patients with hypertension. Am J Hypertens. 2009 Apr;22(4):392-6. PMID:19180061

30. Panjabi S, Lacey M, Bancroft T, Cao F. Treatment adherence, clinical outcomes, and economics of triple-drug therapy in hypertensive patients. J Am Soc Hypertens. 2013 JanFeb;7(1):46-60. PMID:23321404

31. Hsu CN, Wang TD. Secular trends in prescription patterns of single-pill combinations of an angiotensin-converting enzyme inhibitor or angiotensin receptor blocker plus a thiazide diuretic for hypertensive patients in Taiwan. Acta Cardiol Sin. 2013;29(1):49-55.

32. Erkens JA, Panneman MMJ, Klungel OH, van den Boom G, Prescott MF, Herings RM. Differences in antihypertensive drug persistence associated with drug class and gender: a PHARMO study. Pharmacoepidemiol Drug Saf. 2005 Nov;14(11):795-803. PMID:16178043

33. Natarajan N, Putnam W, Van Aarsen K, Beverley Lawson $\mathrm{K}$, Burge $\mathrm{F}$. Adherence to antihypertensive medications among family practice patients with diabetes mellitus and hypertension. Can Fam Physician. 2013 Feb;59(2):e93-100. PMID:23418264

34. Okoro RN, Ngong CA. Assessment of patient's antihypertensive medication adherence level in non-comorbid hypertension in a tertiary hospital in Nigeria. Int J Pharma Bio Sci. 2012;3(2):47-54.

35. Gascón J, Sánchez-Ortuño M, Llor B, Skidmore D, Saturno PJ; Treatment Compliance in Hypertension Study Group. Why hypertensive patients do not comply with the treatment: results from a qualitative study. Fam Pract. 2004 Apr;21(2):125-30. PMID:15020377

36. Hashmi SK, Afridi MB, Abbas K, Sajwani RA, Saleheen D, Frossard PM, et al. Factors associated with adherence to antihypertensive treatment in Pakistan. PLoS One. 2007;2(3):e280. PMID:17356691

37. Stavropoulou C. Non-adherence to medication and doctorpatient relationship: Evidence from a European survey. Patient Educ Couns. 2011 Apr;83(1):7-13. PMID:20541884

38. Huang S, Chen Y, Zhou J, Wang J. Use of family member-based supervision in the management of patients with hypertension in rural China. Patient Prefer Adherence. 2014;8:1035-42. PMID:25114514

39. Zedler BK, Kakad P, Colilla S, Murrelle L, Shah NR. Does packaging with a calendar feature improve adherence to self-administered medication for long-term use? A systematic review. Clin Ther. 2011 Jan;33(1):62-73. PMID:21397775

40. Martin KD, Roter DL, Beach MC, Carson KA, Cooper LA. Physician communication behaviors and trust among black and white patients with hypertension. Med Care. 2013 Feb;51(2):1517. PMID:23132201

41. Alhalaiqa F, Deane KHO, Gray R. Hypertensive patients' experience with adherence therapy for enhancing medication compliance: a qualitative exploration. J Clin Nurs. 2013 Jul;22(13-14):2039-52. PMID:23441835

42. Ponnusankar S, Surulivelrajan M, Anandamoorthy N, Suresh B. Assessment of impact of medication counseling on patients medication knowledge and compliance in an outpatient clinic in South India. Patient Educ Couns. 2004 Jul;54(1):55-60. PMID:15210260

43. Vincze G, Barner JC, Bohman T, Linn WD, Wilson JP, Johnsrud MT, et al. Use of antihypertensive medications among United States veterans newly diagnosed with hypertension. Curr Med Res Opin. 2008 Mar;24(3):795-805. PMID:18252038 